\title{
Compact Rhombus Ring Dual Frequency Microstrip Antenna for Wireless Applications
}

\author{
D. Nataraj, J.Prasanth Kumar, B.Rama Rao, G.Karunakar
}

\begin{abstract}
In paper, a low profile microstrip patch antenna with rhombus model is designed at an running frequency at $2.4 \mathrm{GHz}$, 5.2 GHz. Microstrip Patch Antenna are suited to non-plane and plane areas, uncomplicated and effortless to design by used Printed Circuit Technology, it is a mechanically vigorous when it is ascended on rigid places and when the particular patch design model and dimension were selected, it has adjustable in view of resonance frequency, radiation design, impedance and polarization. High Frequency Structural Simulator (HFSS) is a definite component method solver for structures of EM (electromagnetic). The outcome values are discussed and analyzed in view of $S_{11}$ (Return Loss), $3 D$ Polar Plot, Radiation design and Gain. The value of $S_{11}$ comes out to be $-14.16 \mathrm{~dB}$ for the designed antenna. The antenna measured length is nearly half wavelength in the dielectric, it is a highly censorious parameter, which governs the antenna resonant frequency. And the final values are simulated using High Frequency Structural Simulator.
\end{abstract}

Keywords : Microstrip, Antenna, microwave, HFSS

\section{INTRODUCTION}

Proposed Antenna have appeared among investigators because of their interesting features like light weight, low volume, low profile and conformal to ascend structures, but it has two serious disadvantages, low gain and narrow bandwidth [1]. However, the large restriction associate along MSPA is their narrow bandwidth [2-3] which regulates owned much functional application. There are many times have been given in the literature whereas increasing bandwidth [4-7]. Different models have been proposed to get multi frequency signals, similarly, by used sloted patch, the patch loading with short pins [10], used load slits[6], use assembled proposed antenna [8-9]. Although antenna working at more number of multi band of frequencies and their gain enhancement are found infrequently. Hence a constructed Rhombus MSP Antenna convenient for MMD and GPS applications.

The author [5] was described a solution of novel compact for integrating a GPS and a SDARS (Satellite Digital Audio Radio Service) antenna in a very small size to satisfy automotive market. The GPS antenna is a little patch antenna and SDARS antenna designed in sequence to fit in the assuaged space without changing band and radiation efficiency ofGPS antenna. The geometry of SDARS basic is a Rhombus-Ring Microstrip Antenna functioning in to the range offrequency $2.03-2.98 \mathrm{GHz}$ with LHCP (lefthand

Revised Manuscript Received on December 13, 2019.

D. Nataraj, Assoc. Prof., ECE Dept. Pragati Engg. College (A), Kakinada, Surampalem, A.P., India: dasari.nataraj@gmail.com Engg., Eluru, A.P., India

Dr.B.Rama Rao, Prof. Dept. of ECE, Aditya Inst. of Tech. \& Magt, Tekkali, A.P., India

Dr.G.Karunakar, Associate Professor. Dept of ECE, Gitam Inst. of Tech. GITAM (Deemed to be University). Visakhapatnami, A.P., India
J.Prasanth Kumar, Assoc. Prof., ECE Dept., Ramachandra College of

profkarunakar@gmail.com

circular polarization) and it is protected over the GPS patch, it received a RHCP (right hand circular polarization) signal at $1.455 \mathrm{GHz}$. The complete volume of the antenna solution is only $27 \times 29 \times 7.6 \mathrm{~mm}^{3}$, renders it attractive in automotive field.

\section{ANTENNA DESIGN EQUATIONS}

The location and fitting of the antenna in regards to its patch width, patch length, ground plane and reflector are mathematically analyzed and ascertained its usage [1].

$$
w=\frac{c}{2 f\left(\frac{\epsilon_{r}+1}{2}\right)^{1 / 2}}
$$

The effective value of Dielectric constant $\varepsilon_{\text {eeff }}$ is mentioned as

$$
\varepsilon_{\text {eff }}=\frac{\varepsilon_{r}+1}{2}+\frac{\varepsilon_{r}-1}{2}\left[\frac{1}{\sqrt{\left(1+\frac{12 h}{w}\right)}}\right]
$$

The patch dimensions are extended to account the fringing effects.

The extension is given as,

$$
\Delta L=0.412 h \frac{\left(\varepsilon_{\text {eff }}+0.3\right)\left(\frac{W}{h}+0.264\right)}{\left(\varepsilon_{\text {eff }}-0.258\right)\left(\frac{W}{h}+0.8\right)}
$$

Since the extended length has been on each side of the patch, As mentioned effective length,

$$
L_{\text {eff }}=\frac{c}{2 f\left(\epsilon_{\text {reff }}\right)^{1 / 2}}
$$

Patch actual length $\mathrm{L}$ is mentioned as,

$$
L=L_{e f f}-2 \Delta L
$$

The Ground layer measurements is taken from the following formulae

Ground plane Length

Ground plane Width

$$
\mathrm{L}+6 \mathrm{~h}=\mathrm{L}_{\mathrm{g}}
$$

$$
\mathrm{W}+6 \mathrm{~h}=\mathrm{W}_{\mathrm{g}}(7)
$$

\section{RHOMBUS RING ANTENNA DESIGN}

The Rhombus ring shaped microstrip antenna (RMSA) with line feeding technique is shown in figure 1. The antenna is designed by using substrate made up of glass epoxy thickness is $1.6 \mathrm{~mm}$. Optimized resonating frequency of the designed antenna which is operating at $2.4 \mathrm{GHz}$. The designed antenna with width and length of a radiating patch is $27 \mathrm{mmX} 29 \mathrm{~mm}$

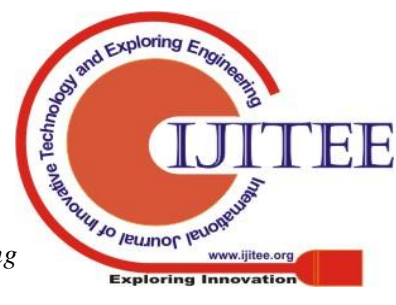




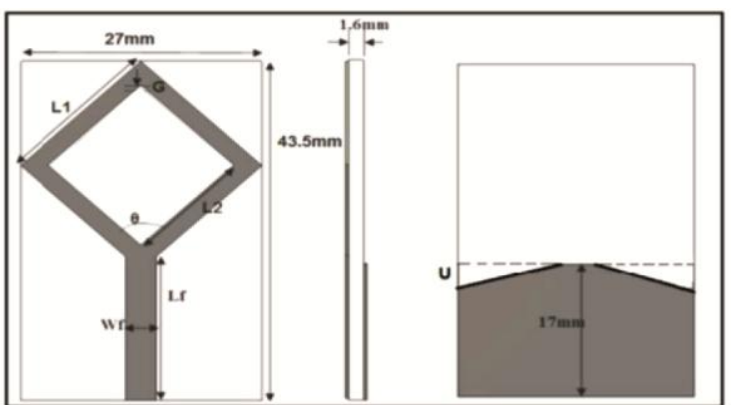

$\begin{array}{lll}\text { a) front view } & \text { b) side view } & \text { c) back view }\end{array}$

Fig.1 Rhombus shaped antenna.

Figure 1 is radiated patch of Rhombic Ring and its microstrip feed line is etched on substrate upper layer of material, while the reduced rectangular ground is on the other side of substrate. The figure 2 shows different simulated views of proposed antenna. The figure 3 shows the return loss results when only the ring is considered and using software to get results. It can be seen that there is extending signal at a frequency of $2.52 \mathrm{GHz}$. The results indicate that the ring connections to the lower band frequency. Referring to Fig. 1, the mean circumferences $\mathrm{Crh}$ of outer were calculated from:

$$
\mathrm{Crh}=2(L 1+L 2)
$$

Table1. Measurements of Rhombic Ring antenna all measurements are in $\mathbf{~ m m}$.

\begin{tabular}{|c|c|c|c|c|}
\hline $\mathrm{L}_{1}$ & $\mathrm{~L}_{2}$ & $\mathrm{~L}_{\mathrm{F}}$ & $\mathrm{W}_{\mathrm{F}}$ & $\Theta$ \\
\hline 19 & 14.8 & 18 & 3.2 & 90 \\
\hline
\end{tabular}

Table: 1 detailed measurements of Rhombus ring antenna. Antenna measurements are in $\mathrm{mm}$. It can be seen that the ratio of wavelength, $d 1$ in the substrate to the mean circumference of the ring is 0.9593 for the first band whose center frequency is at $2.47 \mathrm{GHz}$. These results indicate the strong agreement between the circumference of rings and wavelength of the substrate.

The Proposed Antenna designed initially in HFSS and fig.2 shows views of top and bottom.

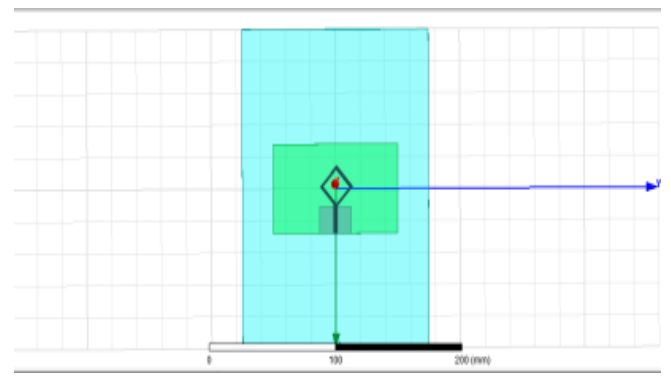

i) Proposed Antenna Elevation View

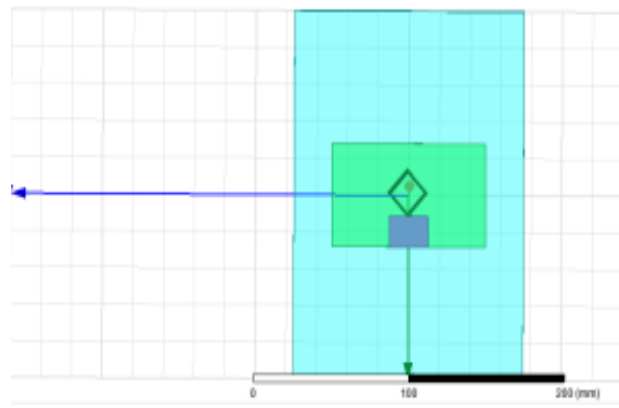

ii) Proposed Antenna Back View. Fig.2 Designed Antenna in HFSS

\section{RESULTS AND DISCUSSIONS}

The performance characteristic of device behaviour obtained in terms of vswr, gain and return loss by simulated, Rhombus MSA with line feed shown in Figure 3, In table 2 summary report of $S_{11}$ (return loss), vswr and gain with respect to vibrate frequency.

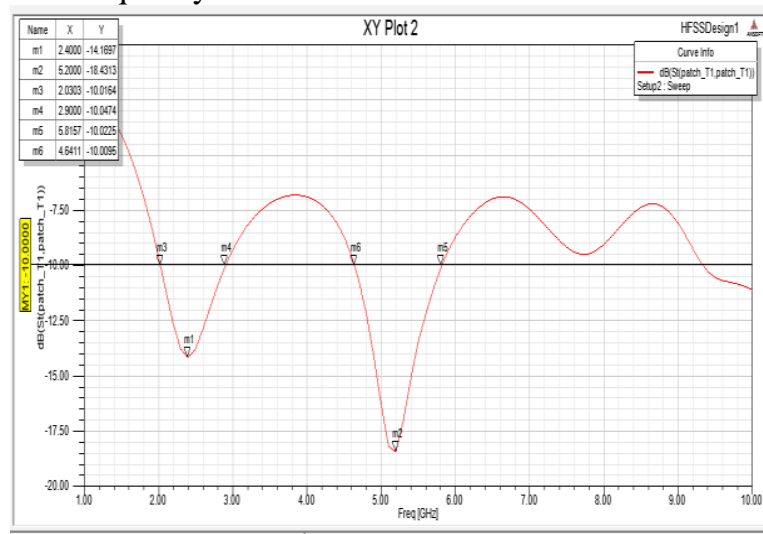

Fig.3: $S_{11}$ Simulated of Rhombic Ring Antenna.

As shown in the above figure 3 . The proposed antenna resonates at two frequency values correspondingly at $2.4 \mathrm{GHz}$ \& $5.2 \mathrm{GHz}$. and $\mathrm{S}_{11}$ is $-14.16 \mathrm{~dB} \&-18.43 \mathrm{~dB}$.

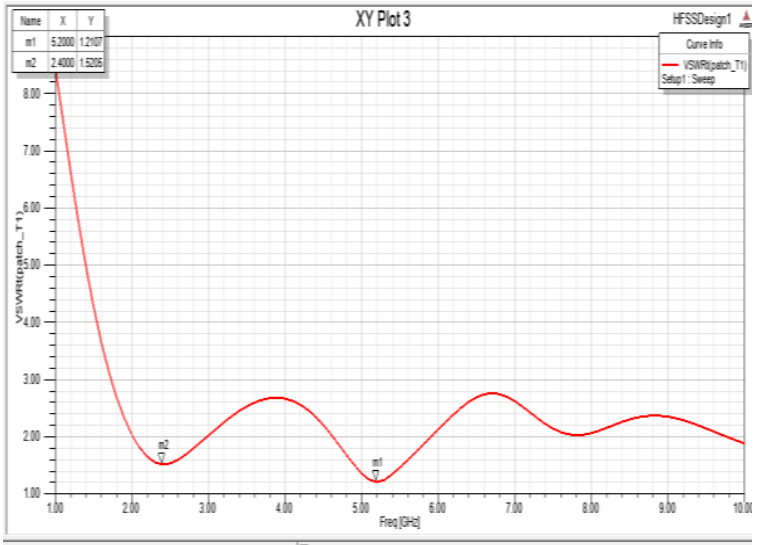

Fig.4: VSWR of Rhombic Ring Antenna.

As shown of the above figure 4.The proposed antenna vibrates at two frequency values correspondingly at $2.4 \mathrm{GHz}$ and $5.2 \mathrm{GHz}$. and VSWR are 1.21 and 1.5.

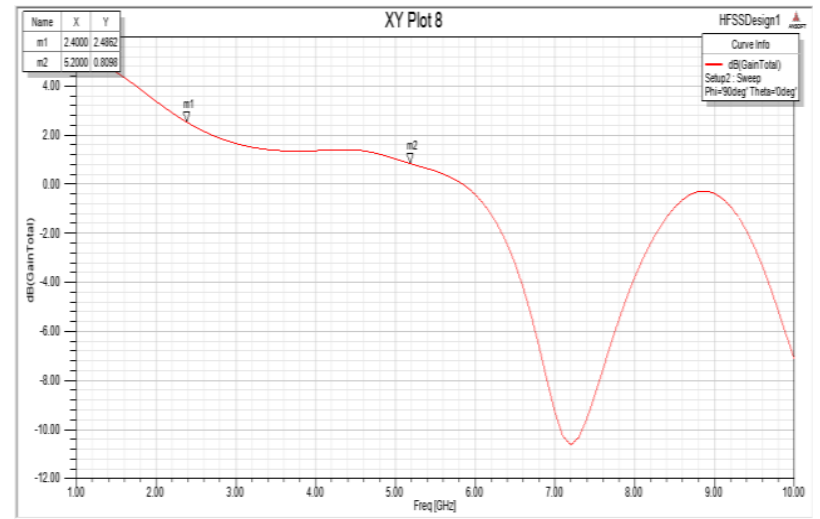

Fig.5: Gain v/s Frequency of Rhombic Ring Antenna As shown in the above figure 5. The proposed antenna resonate two different frequencies correspondingly at 2.4 GHz. and $5.2 \mathrm{GHz}$. and gain is $2.4 \mathrm{~dB}$ and $0.809 \mathrm{~dB}$. 


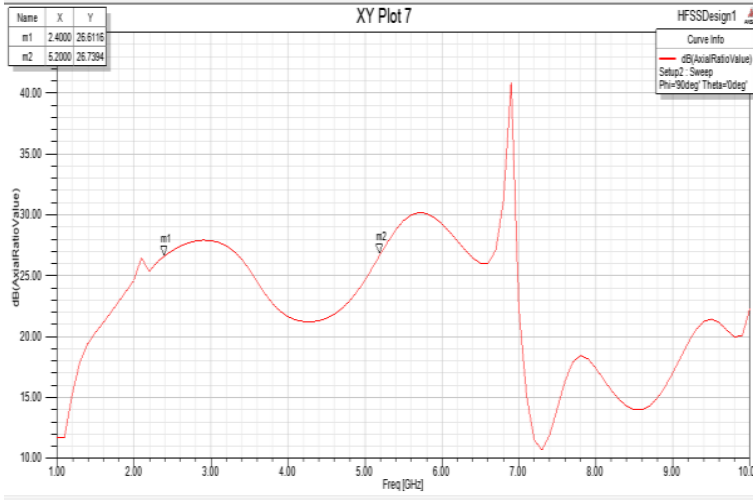

Fig.6: Axial Ratio v/s frequency of Rhombic Ring Antenna

.As shown in the above figure 6 . The proposed antenna vibrates at two frequencies correspondingly at $2.4 \mathrm{GHz}$ and 5.2 GHz. And Axial Ratio are $26.7 \mathrm{~dB}$ and $26.6 \mathrm{~dB}$.

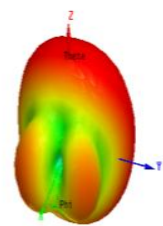

Fig.7: Simulated Gain of Rhombic Ring Antenna As appear in the above figure 7 the proposed antenna of gain is $2.48 \mathrm{~dB}$.

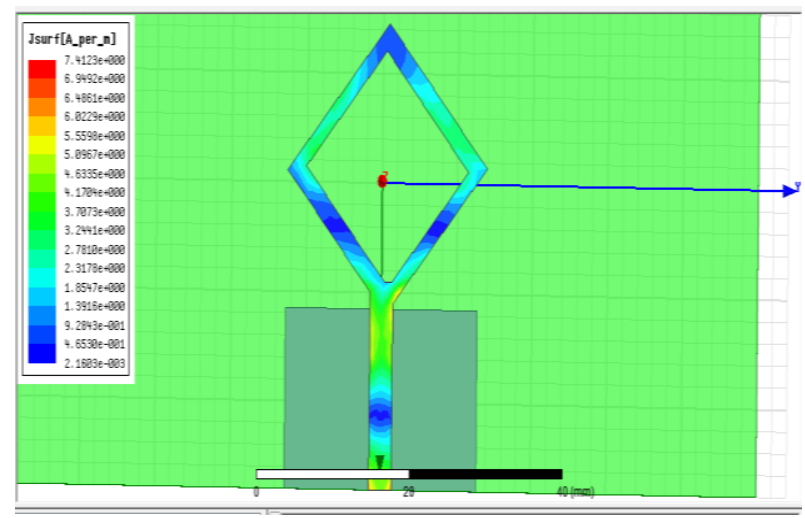

Figure.8: Distributed Current at 5.2GHz vibrates frequency of Rhombic Ring Antenna.

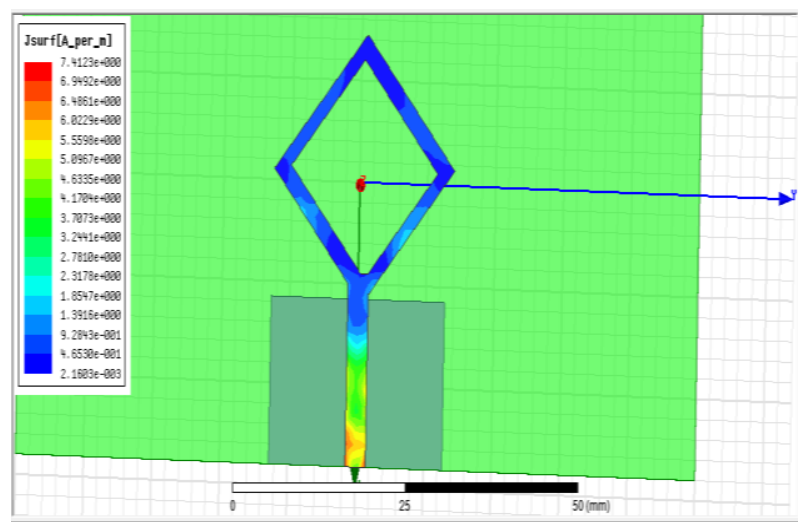

Fig.9: Distributed Current at 2.4GHz frequency of Rhombic Ring Antenna.
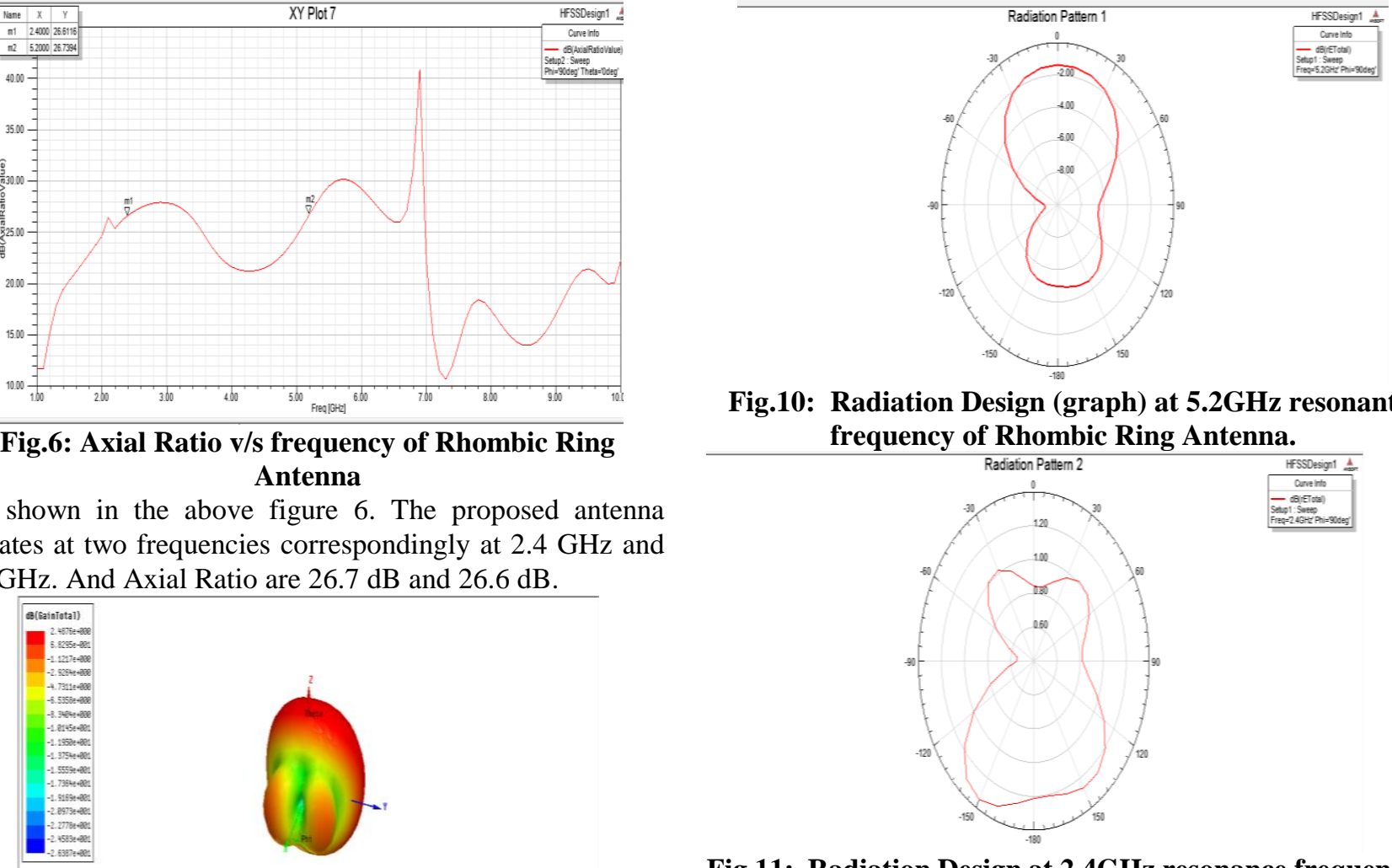

Fig.10: Radiation Design (graph) at 5.2GHz resonant frequency of Rhombic Ring Antenna.

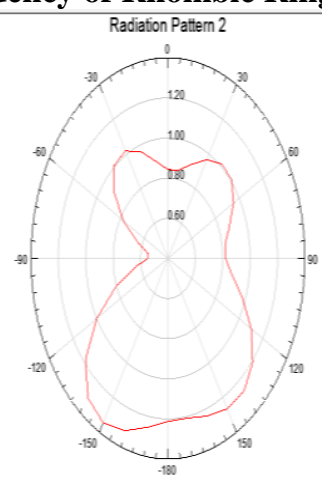

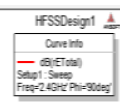

Fig.11: Radiation Design at 2.4GHz resonance frequency of Rhombic Ring Antenna.

Table.2 :Comparison of parameters of Rhombus antenna

\begin{tabular}{|c|c|c|c|c|c|}
\hline $\begin{array}{c}\text { Resonance } \\
\text { Frequency } \\
\mathrm{GHz}\end{array}$ & $\begin{array}{l}\text { Retur } \\
\text { n Loss } \\
(\mathrm{dB})\end{array}$ & VSWR & $\begin{array}{c}\text { Band } \\
\text { (microwa } \\
\text { ve) }\end{array}$ & $\begin{array}{l}\text { Gain } \\
\text { (dB) }\end{array}$ & $\begin{array}{l}\text { Applicati } \\
\text { ons }\end{array}$ \\
\hline 2.4 & -14.16 & 1.52 & S & & $\begin{array}{l}\text { Wi-Fi, } \\
\text { National } \\
\text { Weather } \\
\text { service, } \\
\text { Telecom } \\
\text { municatio }\end{array}$ \\
\hline 5.2 & -18.43 & 1.21 & $X$ & 2.48 & Radar. \\
\hline
\end{tabular}

Figure. 8 shows distribution current at $5.2 \mathrm{GHz}$. Resonance frequency of Rhombic Ring Antenna. Figure 9 shows distribution current at $2.4 \mathrm{GHz}$. Resonance frequency of Rhombic Ring Antenna. Figure 10 shows Radiation design at 5.2GHz. Figure 11 shows Radiation design at $2.4 \mathrm{GHz}$ of Rhombic Ring Antenna.

\section{CONCLUSIONS}

The construct and detail of Rhombic Ring Microstrip Patch Antennas for wireless network application have been presented. Fabricated with FR-4 material with suitable measurements. The results of the rhombus ring are far from resonance as $5.2 \mathrm{GHz}$ and $2.4 \mathrm{GHz}$. Return Loss is $-18.43 \mathrm{~dB}$ and $-14.16 \mathrm{~dB}$. VSWR is 1.21 and 1.5 . Gain is $2.48 \mathrm{~dB}$. Applications are Wi-Fi, National Weather service, Telecommunications, Space Radar.

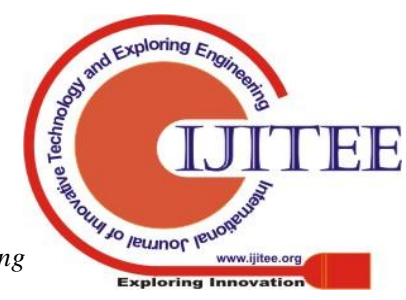




\section{REFERENCES}

1. Kumar G. and KP Ray Broad Band Microstrip Antenna, Artech House, US, 2003.

2. Bahl. I .J and Bhartia. P, Antenna of Microstrip, MA, 1981 Artech House,.

3. Pozar.D.M, antenna of Microstrip, IEEE, Vol. 80, No.1, page 79, 1992.

4. $\quad$ Pues.H.F and Capelle.A.R.V.D, “an Impedance Matching technique for increasing the BW of Microstrip Antenna," IEEE Trans. on Antenna \& Propagation, vol. 37, No. 11, Page no. 1345-54, 1989.

5. Kim.K.Oh.B, and Choi. J, "Design of dual and BW aperture stacked antenna with double-sided notches" ELECTRONIC LETTERS, vol. 40, no. 11, page no. 643-45, 2004

6. Sze.J.Y and Wong. K.. L, "slotted rectangular microstrip antenna for BW enhancement," IEEE Trans. Antenna Propagation, volume 48, no.8, page. $1149-52,2000$.

7. Kumar.Gand Gupta K.C, "Broad-Band microstrip antenna using additional resonator gap-coupled to the Radiating Edges" IEEE Trans .on Antenna and Propagation, volume. 32, Issue 12, page. 1375-79, 1984

8. Nataraj D, and Dr.G.Karunakar."Four Element miniaturized Microstrip Antenna Array using Defected Ground Structure for Satellite Application" Journal of Web Engineering, Vol. 18, No 4 (2019) $5014-5019$

9. J.P Kumar and Dr.G. Karunakar "compact C shaped mimo diversity antenna for QB applications with hexagonal stub for isolation improvement". Int. JRF microwave computer aided eng. 2019.

10. Pan.SC and Wang KL, "dual frequency triangular Microstrip Antenna with A shorting pin" IEEE Trans Antenna propagation., Volume 45, No. 12, page. 1889-91, 2002.

\section{AUTHORS DESCRIPTION}

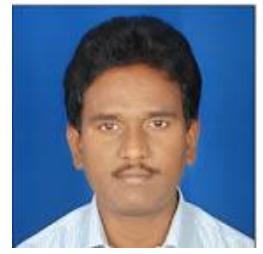

D.Nataraj completed his Master of Engineering in the stream of ECE. (Digital System and Computer Electronic) in the year 2009 from JNTU Hyd College of Engg. JNTUH. He is working as Assoc. professor in Pragati Engineering College (A), Kakinada India. He is currently pursuing his $\mathrm{PhD}$ in Micro strip Antennas from Department of ECE, GITAM Institute of Technology, GITAM Deemed to be University, Visakhapatnam, AP.11publications in microstrip antenna and interested research topics are ultra wide band antennas, MIMO antennas, gain, and bandwidth enhancement in broadband and wideband Antennas using DGS structures and FSS Techniques. He is the Life member of IETE.

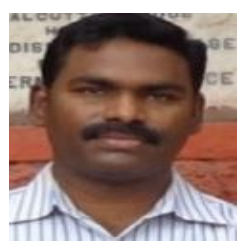

J.Prasanth Kumar.He completed BE in Electronics and Communication Engineering and M.Tech (Microwave Engineering) from Acharya Nagarjuna University, Guntur, year of 2003and 2008. He is currently pursuing his $\mathrm{PhD}$ in Micro strip Antennas from Department of ECE, GIT, GITAM University, Visakhapatnam, AP. He produced 10 publications in microstrip antenna.

$\mathrm{He}$ is also member of IETE, IEANG and ISRD.

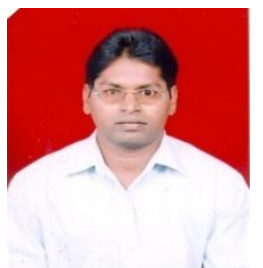

Dr. B.Rama Rao completed his B.E. and Master of Technology in the stream of Electronics and communication Engineering and Radar and microwave engineering in the year of 1998,2004 respectively $\mathrm{He}$ obtained his $\mathrm{Ph} . \mathrm{D}$ from Andhra University in 2015. Now, he is working as Professor in Aditya Institute of Technology And Management, Tekkali, India. He is the Life member of IETE ,ISTE member IEEE. His area of interests are Antenna and propagation ,Microwave and Radars.

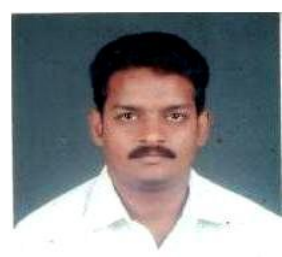

Dr. G. Karunakar completed his B.E. and Master of Engineering in the stream of Electronics and communication Engineering and Radar \& Microwave Engineering in the year of 1996 and 2002 respectively. He obtained his Ph.D from Andhra University in 2013. Now, he is working as Associate Professor in GITAM Institute of Technology GITAM Deemed to be University, Visakhapatnam, India. He has more than 17 years Teaching \& Research Experience. 